\title{
Multi-objective optimization of RO desalination plants
}

\author{
François Vince ${ }^{\mathrm{a}, \mathrm{b} *}$, François Marechal ${ }^{\mathrm{b}}$, Emmanuelle Aoustinn ${ }^{\mathrm{a}}$, Philippe Bréant ${ }^{\mathrm{a}}$ \\ ${ }^{a}$ Veolia Environment Research \& Development, 36-38 Avenue Kléber, 75116 Paris, France \\ ${ }^{b}$ Industrial Energy Systems Laboratory, Ecole Polytechnique Fédérale de Lausanne, \\ 1015 Lausanne, Switzerland \\ email: francois.vince@veolia.com
}

Received 18 February 2007; accepted 25 February 2007

\begin{abstract}
A process optimization method has been developed for the design of reverse osmosis (RO) processes. RO process configurations are systematically generated using a flexible superstructure and evaluated by economical (investment and operating costs), technical (energy requirement, water recovery rate) and environmental performance indicators (Life Cycle Assessment). The simultaneous optimization of the RO process layout and operating conditions constitutes a mixed-integer nonlinear programming (MINLP) problem, which is solved using a multi-objective optimization (MOO) approach. The MOO identifies the best technological alternatives for the set of selected objectives. In a given context, it allows to define a set of optimal solutions representing the trade-off between conflicting objectives such as economical costs and environmental impacts. As a case study, the methodology is applied on a brackish water reverse osmosis (BWRO) desalination project, for which the optimal design is characterized depending on the economical conditions.
\end{abstract}

Keywords: Reverse osmosis (RO) desalination; Process design; Multi-objective optimization; Economical costs; Environmental impacts

\section{Introduction}

\subsection{Context}

Considering the availability of seawater ( $98 \%$ of the water on earth), desalination may represent a major solution when facing the future water scarcity problem [1]. To date, two major technologies

*Corresponding author. are used for desalination: distillation (multi-stage flash MSF or multi-effect evaporation MEE) or membrane filtration (reverse osmosis RO) [2]. For a given potable water supply project, the choice between these desalination processes and other treatment alternatives is yet made on technical, economical and/or political criteria. However recent calls for tender have proven that stakeholders now also seek to integrate sustainability

Presented at the conference on Desalination and the Environment. Sponsored by the European Desalination Society and Center for Research and Technology Hellas (CERTH), Sani Resort, Halkidiki, Greece, April 22-25, 2007. 
factors into their decision process by comparing the environmental impacts of the different alternatives. In response to this environmental concern, the desalination industry is willing to reduce the environmental impacts of these technologies while still proposing competitive water treatment plants. Due to their important energy consumption and to the brine discharge into the local water bodies, desalination plants generate indeed higher potential environmental impacts than potable water production plants using freshwater treatment processes $[3,4]$.

The environmental impacts of desalination plants may be mitigated by extensive downstream (or end-of-pipe) treatments such as concentrate dilution, treatment and disposal [4]. However environmental impacts are usually more effectively reduced by minimizing directly the upstream impact sources through process optimization [5]. The actual performances of the desalination process result from design choices which traditionally aimed at minimizing the total water price (TWP) while respecting technical constraints and project requirements but without explicitly accounting for environmental impact. The environmental performances of the desalination process could be improved by reviewing these previously defined design choices. It is thus proposed to introduce environmental criteria directly in the early design phases, in order to identify new environmental friendly process configurations.

The reverse osmosis (RO) process is constituted of an arrangement of pressure vessels (PV), each of them containing several RO membrane modules connected in series. From a process engineering perspective, the RO process performances can be improved by:

- enhancing the efficiency of the unitary equipments used in the RO process (pretreatment, pumps, energy recovery devices, high permeability membranes, etc.),

- improving the RO process layout and adapting the operating conditions to this layout.
While the improvement of the equipments efficiency is the decisive task of equipment providers and plant operators, process engineers are mainly in charge of designing the process layout and defining operating conditions which meet given project specifications. This requires to make choices over a vast number of options that rely on both continuous (e.g. flow rates) or discontinuous (choice of equipments, interconnections, etc.) variables. At the moment, RO process configurations are still developed using standardized designs based on engineer experience and commercial preferences, with no guarantee that the best performances have been achieved for the technologies available. With the aim of helping the process engineer during the RO process design, an advanced method has therefore been developed for the systematic investigation of the large number of RO process alternatives.

\subsection{Literature review}

$\mathrm{RO}$ process design requires at first to model the unitary equipments composing the process, the most important of which being the RO membrane. Analytical models have been developed to describe the transport phenomenon across the RO membrane [6-8]. These membrane models are then combined to model the complete RO process. RO process design softwares were developed by membrane constructors such as ROSA $^{\odot}$ from FILMTEC ${ }^{\mathrm{TM}}$ [9] or IMSDesign ${ }^{\circledR}$ from Hydranautics ${ }^{\mathrm{TM}}$ [10]. Besides defining constructor good practices for membrane operation and shortcuts methods for pressure vessel modeling, these softwares allowed to test flexible RO configurations for different commercial membranes. Unfortunately these calculations were performed within a black box, without characterizing the membrane-specific parameters. There was furthermore no optimization procedure proposed. A first step toward process optimization was the sensitivity analysis is performed by 
Evangelista and Al-Bastaki [11,12] on a detailed model of a multi-staged hollow fiber membrane configuration. Similarly, McCutchan and Goel [13] modeled two-stages and three-stages configurations of tubular membranes, in order to minimize the operating pressure and the total membrane area [13]. Van der Meer et al. [14] modeled multi-stages spiral-wound membrane PV configurations for permeate production increase. Malek et al. [15] analyzed the costs of one-stage and two-stages hollow fiber RO processes. These studies were however limited to a parametric analysis on predefined RO process configurations without using a systematic design method. El-Halwagi [16] first formulated the reverse osmosis network (RON) optimization problem as a mixed integer nonlinear programming (MINLP) problem and proposed a resolution method for the cost minimization of the hollow fiber membranes RON in waste reduction applications. Voros and Fazilet [17,18] simplified El-Halwagi's representation by using a variable split ratio to formulate the problem as a nonlinear programming (NLP) problem. Marcovecchio et al. [19] proposed an iterative resolution method for the optimization of the total annual cost of either one-stage or two-stage hollow fiber PV configurations. However in these papers, the commonly used spiral-wound membranes pressure vessel was not considered, thus leading to membrane-specific results difficult to compare with actual desalination practices. More over the optimization procedure was performed on a restricted number of process configurations, which did not allow one to identify innovative process options. More recently, Lu et al. [21] used the El-Halwagi problem formulation for the optimization of spiral-wound PV process configurations. Although the spiral-wound PV was modeled globally as a spiral-wound membrane, this study provided some useful results on cost-optimal RO process configurations as a function of project specifications. The optimization was however performed on economical costs only. In a broader perspective, none of the optimization methods reviewed took into account the environmental impact of the RO desalination plant.

\subsection{Problem statement concerning the RO process design}

When developing new processes, the conceptual process design consists in identifying the best process configurations in a given context, so that they may later be detailed by process engineers. A process configuration corresponds to a list of equipments interconnected in a given process layout, for which specific sizes and operating conditions are defined. Referring to Fig. 1, the process design is realized in several steps. The process synthesis consists in systematically generating process configurations. The process characterization represents the performances evaluation of the generated process configurations while the process optimization aims at selecting the best configurations according to a given objective function [5]. RO process design therefore requires three key components:

- The technical modeling of RO equipments and a systematic method for RO process synthesis.

- Accurate performances indicators for RO process characterization.

- An optimization procedure for RO process optimization problem.

As stated in the literature review, RO process optimization has already been developed for given membrane types and process configurations. Nevertheless the results of these studies were difficult to interpret within the framework of actual industrial practices. Indeed most of these studies did not analyze the most commonly used technology, e.g. spiral-wound membrane. This work will therefore focus on the technical modeling and the performances evaluation of spiral-wound membrane PVs. Moreover, these 


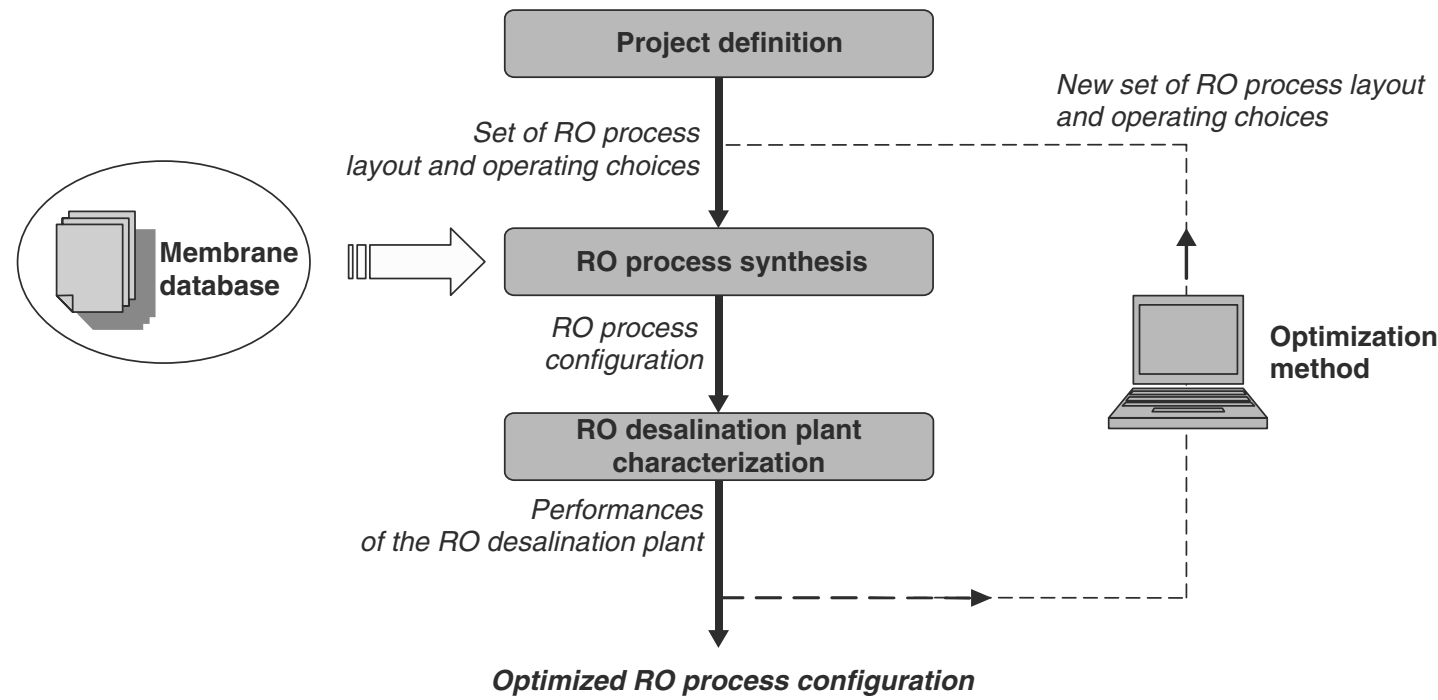

Fig. 1. RO process design method.

optimizations were restrained to a limited number of process configurations in a given local context, thus narrowing the optimization pertinence. A special attention has therefore been paid to the flexibility of the RO process synthesis and to the assessment of local context influence (temperature, water resource quality, etc.). Regarding $\mathrm{RO}$ process characterization, it has been confirmed that the environmental impacts of desalination were not considered during RO process design. Besides defining environmental performance indicators for $\mathrm{RO}$ desalination plants, the proposed design method ought therefore to integrate simultaneously economical and environmental objectives. A computeraided optimization methodology has thus been developed, which:

(i) includes a database of up-to-date RO membrane models,

(ii) performs the systematic generation of all feasible RO process configurations (process layout and operating conditions) with respect to project specifications and local context, (iii) evaluates the technical, economical and environmental performances of these configurations,

(iv) optimizes the RO process configuration within a multi-objective framework.

A case study presents the information which may be generated by applying such methodology.

\section{RO process synthesis}

\subsection{RO membrane}

Lonsdale et al. [6] first presented a membrane transport model assuming the homogeneous diffusion of solvent and solute across a nonporous membrane. Finely porous models were developed by Kimura and Sourirajan [7] to take into account convective effects inside the membrane. Spiegler, Kedem and Katchalsky [8,22] used a thermodynamic approach to describe the whole transport phenomena inside the membrane. These models can be resumed to a two parameters solution-diffusion model which assumes that both the solute and solvent dissolve in the 
surface layer of the membrane and diffuse through the membrane depending on two parameters: the membrane pure water permeability $A$ and the membrane solute permeability $B$. The interface between solution and membrane layer has also been studied. At the RO membrane interface, the most relevant phenomenon is the concentration polarization due to solute retention on the membrane layer. Several studies were conducted by Kimura and Sourirajan [23] and Taylor et al. [24], which correlated concentration polarization with membrane characteristics, feedwater solute concentration and permeate flux. These models describe the water and salts fluxes per unit area of RO membrane. They therefore have to be integrated over the whole membrane surface in order to model the performances of a $\mathrm{RO}$ membrane module. Sirkar et al. [25], Gupta [26] provided shortcut methods in order to take into account the feedwater salts concentration increase and the pressure drop along the membrane feed and permeate channels (Fig. 2).

This work aims at generating $\mathrm{RO}$ process configurations which easily integrate new membranes. The Kimura-Sourirajan two parameters membrane model [23] has thus been used and adapted according to membrane constructor practices. In a first approach, a focus is made on spiral-wound membranes in accordance with actual market trends [2]. The boron presence is not taken into account. The membrane is considered to be isothermal. The mass of salts in seawater is considered to be negligible in comparison with the mass of water and the seawater density $\rho$ is considered to be constant at $1000 \mathrm{~kg} \cdot \mathrm{m}^{-3}$.

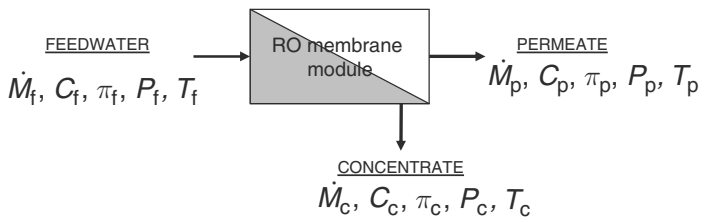

Fig. 2. Schematic diagram of single RO membrane.
The membrane permeate mass flow rate $\dot{M}_{\mathrm{p}}$ is equal to

$\dot{M}_{\mathrm{p}}=\left(J_{\mathrm{w}}+J_{\mathrm{s}}\right) \cdot S_{\mathrm{M}}$

with $\dot{M}_{\mathrm{p}}$ the permeate mass flow rate in $\mathrm{kg} \cdot \mathrm{s}^{-1}$, $J_{\mathrm{w}}$ the permeate mass flux through the membrane in $\mathrm{kg} \cdot \mathrm{m}^{-2} \cdot \mathrm{s}^{-1}, J_{\mathrm{s}}$ the salts mass flux through the membrane in $\mathrm{kg} \cdot \mathrm{m}^{-2} \cdot \mathrm{s}^{-1}, S_{\mathrm{M}}$ the membrane active area in $\mathrm{m}^{2}$.

The mass balance of water and salts across the membrane gives

$\dot{M}_{\mathrm{f}}=\dot{M}_{\mathrm{p}}+\dot{M}_{\mathrm{c}}$

$\dot{M}_{\mathrm{f}} \cdot C_{\mathrm{f}}=\dot{M}_{\mathrm{p}} \cdot C_{\mathrm{p}}+\dot{M}_{\mathrm{c}} \cdot C_{\mathrm{c}}$

with $i \in\{f, p, c\}$ respectively the feed, permeate, concentrate water streams, $\dot{M}_{\mathrm{i}}$ the $i$ th water stream mass flow rate in $\mathrm{kg} \cdot \mathrm{s}^{-1}, C_{\mathrm{i}}$ the $i$ th water stream salts mass concentration in $\mathrm{kg}$ of salts per $\mathrm{kg}$ of water.

The water recovery rate $r$ is defined by $r=\frac{\dot{M}_{\mathrm{p}}}{\dot{M}_{\mathrm{f}}}$

The membrane salts rejection rate $\mathrm{R}$ is defined by $\mathrm{R}=1-\frac{C_{\mathrm{p}}}{C_{\mathrm{f}}}$

The permeate mass flux $J_{\mathrm{w}}$ through the membrane is modeled by the Fick's law:

$J_{\mathrm{w}}=A \cdot(\Delta P-\Delta \pi)$

with $J_{\mathrm{w}}$ the permeate mass flux through the membrane in $\mathrm{kg} \cdot \mathrm{m}^{-2} \cdot \mathrm{s}^{-1}, A$ the membrane pure water permeability in $\mathrm{kg} \cdot \mathrm{m}^{-2} \cdot \mathrm{s}^{-1} \cdot \mathrm{Pa}^{-1}$, $\Delta P$ the transmembrane pressure in $\mathrm{Pa}, \Delta \pi$ the transmembrane osmotic pressure in $\mathrm{Pa}$.

The salts mass flux $J_{\mathrm{s}}$ through the membrane is modeled by

$J_{\mathrm{s}}=B \cdot\left(C_{\mathrm{w}}-C_{\mathrm{p}}\right)$

with $J_{\mathrm{s}}$ the salts mass flux through the membrane in $\mathrm{kg} \cdot \mathrm{m}^{-2} \cdot \mathrm{s}^{-1}, B$ the membrane salts 
permeability in $\mathrm{kg} \cdot \mathrm{m}^{-2} \cdot \mathrm{s}^{-1}, C_{\mathrm{w}}$ the wall mass salts concentration in $\mathrm{kg}$ of salts per $\mathrm{kg}$ of water, $C_{\mathrm{p}}$ the permeate mass salts concentration in $\mathrm{kg}$ of salts per $\mathrm{kg}$ of water.

The assumption is made that the mass flux of solute is equal to the mass flux of permeate multiplied by the permeate mass salts concentration:

$J_{\mathrm{s}}=J_{\mathrm{w}} \cdot C_{\mathrm{p}}$

with $J_{\mathrm{s}}$ the salts mass flux through the membrane in $\mathrm{kg} \cdot \mathrm{m}^{-2} \cdot \mathrm{s}^{-1}, J_{\mathrm{w}}$ the permeate mass flux through the membrane in $\mathrm{kg} \cdot \mathrm{m}^{-2} \cdot \mathrm{s}^{-1}, C_{\mathrm{p}}$ the permeate mass salts concentration in $\mathrm{kg}$ of salts per $\mathrm{kg}$ of water.

In a first approach, the concentration polarization factor is evaluated using the correlation developed by Taylor et al. [24] and approximated for spiral-wound membranes by FILMTEC $^{\mathrm{TM}}[9]$ :

$C_{\mathrm{w}}-C_{\mathrm{p}}=\left(\frac{C_{\mathrm{f}}+C_{\mathrm{c}}}{2}-C_{\mathrm{p}}\right) \cdot \mathrm{e}^{K \cdot r}$

with $C_{\mathrm{w}}$ the wall mass salts concentration in $\mathrm{kg}$ of salts per $\mathrm{kg}$ of water, $C_{\mathrm{f}}$ the feedwater mass salts concentration in $\mathrm{kg}$ of salts per $\mathrm{kg}$ of water, $C_{\mathrm{c}}$ the concentrate mass salts concentration in $\mathrm{kg}$ of salts per $\mathrm{kg}$ of water, $C_{\mathrm{p}}$ the concentrate mass salts concentration in $\mathrm{kg}$ of salts per $\mathrm{kg}$ of water, $r$ the water recovery rate of the membrane, $K=0.7$.

The transmembrane pressure $\Delta P$ is calculated with

$\Delta P=P_{\mathrm{f}}-P_{\mathrm{p}}-\frac{\Delta p_{\text {drop }}}{2}$

with $\Delta P$ the transmembrane pressure in $\mathrm{Pa}$, $P_{\mathrm{f}}$ the applied feed pressure in $\mathrm{Pa}, P_{\mathrm{p}}$ the resulting permeate pressure in $\mathrm{Pa}, \Delta p_{\text {drop }}$ the pressure drop along the membrane channel in $\mathrm{Pa}$.

The pressure drop $\Delta p_{\text {drop }}$ is approximated by the correlation defined by Schock and Miquel
[27] and adapted for spiral-wound membranes by FILMTEC ${ }^{\mathrm{TM}}$ [9]:

$\Delta p_{\text {drop }}=\lambda\left(\frac{\dot{M}_{\mathrm{f}}+\dot{M}_{\mathrm{c}}}{2 \cdot \rho}\right)^{\alpha}$

with $\Delta p_{\text {drop }}$ the pressure drop in $\mathrm{Pa}, \dot{M}_{\mathrm{f}}$ the membrane feed flow rate in $\mathrm{kg} \cdot \mathrm{s}^{-1}, \dot{M}_{\mathrm{c}}$ the membrane concentrate flow rate in $\mathrm{kg} \cdot \mathrm{s}^{-1}$, $\alpha=1.7, \lambda=9.5 \times 10^{8}$.

Considering that seawater contains only $\mathrm{NaCl}$ salts, the transmembrane osmotic pressure is approximated by the Van't Hoff relation [28]:

$\Delta \pi=\frac{2 \cdot R \cdot T \cdot \rho}{M_{\mathrm{NaCl}}} \cdot\left(C_{\mathrm{w}}-C_{\mathrm{p}}\right)$

with $\Delta \pi$ the transmembrane osmotic pressure in $\mathrm{Pa}, R$ the universal gases constant, equal to $8.314 \mathrm{~J} \cdot \mathrm{mol}^{-1} \cdot \mathrm{K}^{-1}, T$ the water temperature in $\mathrm{K}, M_{\mathrm{NaCl}}$ the molar mass of $\mathrm{NaCl}$ equal to $0.0585 \mathrm{~kg} \cdot \mathrm{mol}^{-1}, C_{\mathrm{w}}$ the wall salts mass concentration in $\mathrm{kg}$ of salts per $\mathrm{kg}$ of water, $C_{\mathrm{p}}$ the permeate salts mass concentration in $\mathrm{kg}$ of salts per $\mathrm{kg}$ of water.

The membrane water permeability $A$ is approximated as a function of feedwater temperature $T$, transmembrane osmotic pressure $\Delta \pi$ and fouling factor FF by the following relation:

$A=A_{\text {ref }}(\Delta \pi) \cdot \mathrm{FF} \cdot \mathrm{TCF}$

with $A$ the membrane pure water permeability in $\mathrm{kg} \cdot \mathrm{m}^{-2} \cdot \mathrm{s}^{-1} \cdot \mathrm{Pa}^{-1}, A_{\text {ref }}(\Delta \pi)$ the reference permeability in $\mathrm{kg} \cdot \mathrm{m}^{-2} \cdot \mathrm{s}^{-1} \cdot \mathrm{Pa}^{-1}$ at $T_{0}=298 \mathrm{~K}$ without fouling, TCF the temperature correction factor at $T, \mathrm{FF}$ the fouling factor.

The influence of membrane fouling on membrane permeability is expressed by the fouling factor FF which varies between $100 \%$ for new membranes and $80 \%$ for 4 years old membranes [9]. 
The influence of temperature on membrane permeability is expressed by the temperature correction factor TCF using a Arrhenius type correlation [29]:

$\mathrm{TCF}=\mathrm{e}^{\frac{e}{R}\left(\frac{1}{T_{0}}-\frac{1}{T}\right)}$

with $T$ the water temperature in $\mathrm{K}, T_{0}$ the reference water temperature equal to $298 \mathrm{~K}$, $e$ the membrane activation energy in $\mathrm{J} \mathrm{mol}^{-1}, R$ the universal gases constant equal to $8.314 \mathrm{~J} \mathrm{~mol}^{-1} \mathrm{~K}^{-1}$.

Based on DOW technical documentation, $e$ is estimated for all reverse osmosis membranes at $25,000 \mathrm{~J} \mathrm{~mol}^{-1}$ when $T \leq 298 \mathrm{~K}$ and at 22,000 $\mathrm{J} \mathrm{mol}^{-1}$ when $T>298 \mathrm{~K}$ [9].

For each membrane, the influence of the osmotic pressure $\Delta \pi$ on the reference pure water permeability $A_{\text {ref }}(\Delta \pi)$ has been measured experimentally at $T_{0}=298 \mathrm{~K}$ and $\mathrm{FF}=1$ by membrane producers. An example was published in the FILMTEC ${ }^{\mathrm{TM}}$ technical documentation for the 8-inch BW30 membrane [9]. However in most cases, this relation is not provided. In a first approach, $A_{\text {ref }}(\Delta \pi)$ is therefore considered to be constant and labeled $A_{\text {ref }}$.

In accordance with the papers reviewed, the membrane salts permeability $B$ is considered to be constant $[6,23]$.

Table 1

Membrane database used for RO process synthesis

\subsection{Membrane characterization}

Using the developed RO membrane model, three membrane-specific parameters are sufficient to characterize the filtration across a given type of spiral-wound membrane:

- the membrane active surface $S_{\mathrm{M}}$,

- the membrane reference pure water permeability $\bar{A}_{\text {ref }}$,

- the membrane salts permeability constant $B$.

For each membrane in the membrane database, these 3 parameters are identified using constructor data and experts validation $[9,21]$. Besides hydraulic limits are defined by constructor specifications [9] for membrane filtration good practices (maximum pressure, maximum and minimum flux). A unitary base cost $p_{\text {Mbne }}$ is also fixed for each membrane module using market estimation and cost evaluation from $\mathrm{Lu}$ et al. [21]. At the moment, two commercial membranes (SW30-HR380 and BW30LE-440 from FILMTEC ${ }^{\mathrm{TM}}$ ) are characterized and tested in the generated $\mathrm{RO}$ process configurations (Table 1).

For a characterized membrane type, the membrane model requires therefore 6 values to fully define the membrane operation:

\begin{tabular}{|c|c|c|c|}
\hline \multirow[t]{2}{*}{ Membrane specific parameter } & \multirow[t]{2}{*}{ Unit } & \multicolumn{2}{|c|}{ Membrane type Mbne } \\
\hline & & SW30-HR380 & BW30LE-440 \\
\hline Active surface $S_{\mathrm{M}}$ & $\mathrm{m}^{2}$ & 35.3 & 40.9 \\
\hline Reference pure water permeability $\bar{A}_{\text {ref }}$ & $10^{-9} \mathrm{~kg} \cdot \mathrm{m}^{-2} \cdot \mathrm{s}^{-1} \mathrm{~Pa}^{-1}$ & 2.5 & 12 \\
\hline Salts permeability constant $B$ & $10^{-5} \mathrm{~kg} \mathrm{~m}^{-2} \mathrm{~s}^{-1}$ & 2.5 & 15 \\
\hline Maximum applied TMP $\Delta P_{\max }$ & bar & 68.9 & 41.3 \\
\hline Maximum permeate flux $J_{\mathrm{w}}$ & $\mathrm{LMH}$ or $\mathrm{L} \cdot \mathrm{m}^{-2} \cdot \mathrm{s}^{-1}$ & 47 & 47 \\
\hline Maximum feed flux $\dot{M}_{\mathrm{f}}$ & $\mathrm{m}^{3} / \mathrm{h}$ & 16.2 & 17 \\
\hline Minimum concentrate flux $\dot{M}_{\mathrm{b}}$ & $\mathrm{m}^{3} / \mathrm{h}$ & 2.27 & 2.27 \\
\hline Maximum recovery rate $r_{\max } b_{\min }$ & $\%$ & 30 & 30 \\
\hline Unitary module cost $p_{\mathrm{Mbne}}$ & $\$$ & 1000 & 900 \\
\hline
\end{tabular}


- Mbne the type of membrane in the database,

- $C_{\mathrm{f}}$ the membrane feedwater salinity (in $\mathrm{kg}$ of salts per kg of water),

- $T_{\mathrm{f}}$ the membrane feedwater temperature (in $\mathrm{K}$ ),

- FF the fouling factor of the membrane (in \%),

- $r$ the membrane water recovery rate (in \%),

- $J_{\mathrm{w}}$ the permeate mass flux (in $\mathrm{kg} \cdot \mathrm{m}^{-2} \cdot \mathrm{s}^{-1}$ ).

\subsection{Pressure vessels}

A pressure vessel containing $n_{\mathrm{e}}$ membrane elements is equivalent to $n_{\mathrm{e}}$ staged membranes in series (Fig. 3). The PV permeate is considered to be the mix of the $n_{\mathrm{e}}$ membrane module permeates. The PV recovery rate $\bar{r}$ is therefore defined by

$$
\bar{r}=r_{1}+\sum_{k=2}^{n_{\mathrm{e}}}\left[r_{k} \cdot \prod_{l=1}^{k-1}\left(1-r_{l}\right)\right]
$$

with $r_{k}$ - the water recovery rate of the membrane $k$ for $k=1 \ldots n_{\mathrm{e}}$.

The pressure vessel is modeled as $n_{\mathrm{e}}$ successive membranes defined by Eqs. (1-12). This corresponds to an equations system with $6 . n_{\mathrm{e}}$ degrees of freedom. Assuming that the PV is isothermal and that it contains the same type of membrane modules with the same fouling factor eliminates 3. $n_{e}-3$ degrees of freedom.

For $k=2 \ldots n_{\mathrm{e}}$, the concentrate flow rate, salinity and pressure of membrane $k-1$ are respectively the feedwater flow rate, salinity and pressure of membrane $k$ :

$$
J_{\mathrm{w}}^{k}=\frac{J_{\mathrm{w}}^{k-1} \cdot\left(1-r_{k-1}\right)}{r_{k-1}} \quad \text { for } k=2 \ldots n_{\mathrm{e}}
$$

$$
\begin{array}{ll}
C_{\mathrm{f}}^{k}=C_{\mathrm{b}}^{k-1} & \text { for } k=2 \ldots n_{\mathrm{e}} \\
P_{\mathrm{f}}^{k}=P_{\mathrm{b}}^{k-1} & \text { for } k=2 \ldots n_{\mathrm{e}}
\end{array}
$$

with $J_{\mathrm{w}}^{\mathrm{k}}$ the permeate mass flux through the membrane $k$ in $\mathrm{kg} \mathrm{m}^{-2} \mathrm{~s}^{-1}, C_{\mathrm{f}}^{k}, C_{\mathrm{b}}^{k}$ the feedwater and concentrate mass salts concentration of the membrane $k$, the feedwater and concentrate pressure of the membrane $k$ in $\mathrm{Pa}$.

Eqs. (14-16) allow to eliminate $3 n_{\mathrm{e}}-3$ degrees of freedom. Considering the number of membranes in the PV as a variable $n_{\mathrm{e}}$, the PV model requires 7 values to fully characterize the PV performances (transmembrane pressure applied, permeate salinity...):

- $n_{\mathrm{e}}$ the number of membrane modules in the pressure vessel,

- Mbne the type of membrane module in the database,

- $C_{\mathrm{f}}^{1}$ the feedwater salinity of the first membrane (in $\mathrm{kg}$ of salts per $\mathrm{kg}$ of water),

- $\bar{r}$ the total recovery rate of the pressure vessel (in \%),

- $T_{\mathrm{f}}^{1}$ the temperature of the water stream feeding the PV (in \%),

- FF the fouling factor of the pressure vessel (in \%),

- $J_{\mathrm{w}}^{1}$ the permeate mass flux of the first PV membrane (in $\mathrm{kg} \cdot \mathrm{m}^{-2} \cdot \mathrm{s}^{-1}$ ).

The model is solved using a Newton-Raphson based algorithm. Within the pressure vessel, each membrane is characterized by its individual recovery rate, permeate flux and rejection rate, which allows to verify the PV feasibility based on constructor good practices.

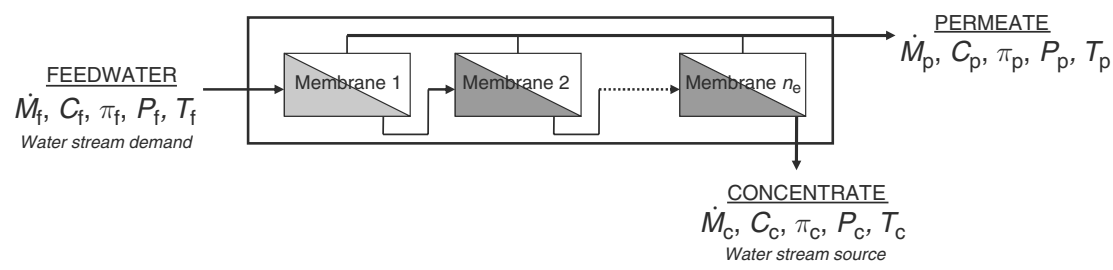

Fig. 3. Schematic representation of a pressure vessel containing $n_{\mathrm{e}}$ spiral-wound membranes. 


\subsection{RO network and superstructure}

The RO process design is decomposed into two related sub-problems. The master optimization problem concerns the characterization of pressure vessels while the lower level optimization problem computes the process layout and the operating conditions for the specified pressure vessels. Two subsets of decisions variables are defined in order to solve the global optimization problem.

A first subset of decision variables is used to establish explicitly the characteristics of $n$ different pressure vessels with 7 decision variables per pressure vessel corresponding to the 7 degrees of freedom of the PV model. Each pressure vessel is represented as two water stream sources (permeate and concentrate) and one water stream demand (pressure vessel feedwater) whose salinity and flow rates are defined by the decision variables (Fig. 3). The $n$ pressure vessels are implemented as individual process units within a superstructure which is defined by systematically generating all the possible connections between the sources and demands, thus allowing for permeate and brine recirculation or blending, staging. An example of superstructure for 2 pressure vessels is presented in Fig. 4. A feasible connection network is a selection of pressure vessels, connecting pipes, mixers, splitters characterized by water stream flows and capacity factors, which forms a RO process configuration that satisfies the project specifications, i.e. the produced potable water salinity and flow requirements. For the given set of pressure vessels, the optimization of the connection network is formulated as a mixed integer linear programming (MILP) problem, which is solved using a conventional branch and bound algorithm. The second subset of decision variables is used to introduce relaxation factors in the objective function of this lower level optimization problem, in order to ensure the global optimality of the generated configurations within the master optimization problem. The detailed decomposition procedure of the MINLP optimization problem is given in [30].

This flexible definition of RO process configurations allows to identify innovative RO configurations adapted to the project constraints

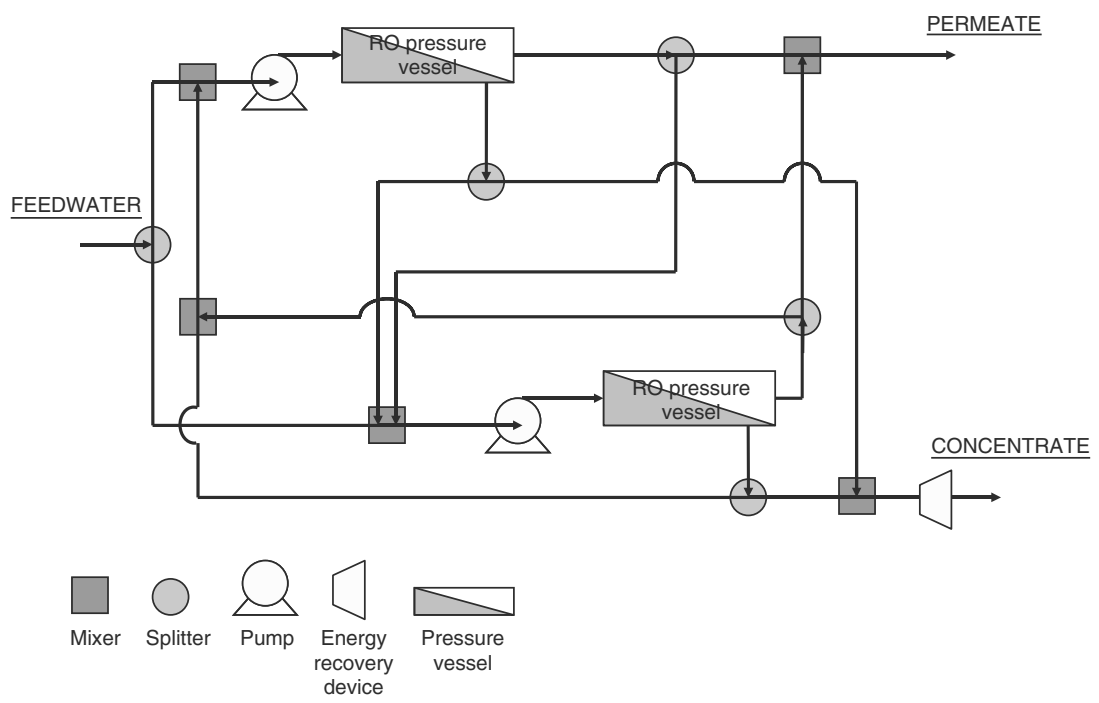

Fig. 4. Superstructure for 2 pressure vessels. 
(e.g. feedwater salinity) without having to specify a predefined arrangement.

\section{RO desalination plant characterization}

In order to characterize their performances, the generated $\mathrm{RO}$ process configurations are integrated into the complete desalination process chain (Fig. 5). The performances of the corresponding $\mathrm{RO}$ desalination plant are assessed by technical, economical and environmental indicators which are used as objective functions of the master optimization problem.

Being part of project specifications, the potable water distribution is identical for all generated plants and may therefore be ignored during the performance evaluation.

\subsection{Technical performances}

The technical characteristics of the RO process configurations (total water recovery rate, electricity consumption, number of pressure vessels, installed power of pumps and pressure exchangers, lengths and diameters of the connecting pipes) are calculated as a function of the project specifications (e.g. permeate production capacity).

In the model, the pumping system efficiency $\eta_{\text {pump }}$ accounting for the pump and the electric motor is assumed to be equal to $80 \%$ and $\eta_{\text {PX }}$ the efficiency of the pressure exchangers used for energy recovery is set at $95 \%$.

The intake pumping depends on the feedwater flow rate and on the type of water intake (beach well, open water intake...). In the present analysis, the electricity consumption for intake pumping is considered to be null.

The pretreatment is considered to be composed of standard coagulation, filtration and prefiltration steps whose average characteristics (injected doses of chemicals, prefilters backwash flow rate...) are calculated as a function of feedwater flow rate. According to site measurements, the pretreatment water recovery rate is considered to be equal to $99 \%$ (due to discharges of filter backwash). The electricity consumed for the pretreatment is estimated at 0.025 $\mathrm{kW} \mathrm{h} / \mathrm{m}^{3}$ of feedwater.

The post-treatment depends on the permeate salinity and on the permeate flow rate which is defined initially by project specifications. The electricity consumption for the post-treatment is considered to be null and its water recovery rate is equal to $100 \%$.

The plant electricity consumption by $\mathrm{m}^{3}$ of potable water produced and the plant water recovery rate in $\mathrm{m}^{3}$ of potable water by $\mathrm{m}^{3}$ of feedwater are deduced from the calculations of these successive treatment steps. They are used as technical performance indicators of the desalination plant for the MOO.

\subsection{Cost evaluation}

Cost analyses on RO desalination plants were published by Wade [31], Ebrahim and AbdelJawad [32], Darwish et al. [33] and more recently by Dreyzin [34] on the Ashkelon RO desalination

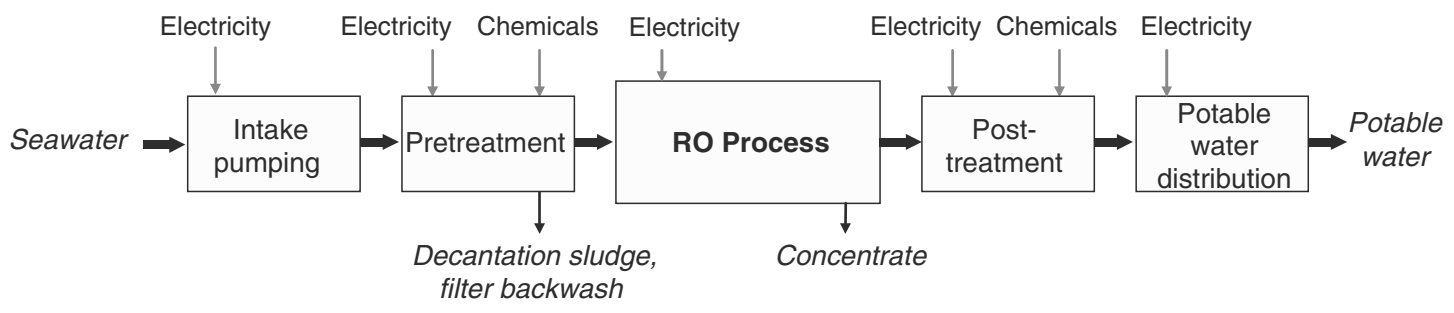

Fig. 5. Process chain of the RO desalination plant. 
plant. These case studies were however highly site-specific and could not be extrapolated to other RO configurations. In a broader perspective, Sommariva [35] carried out a large cost review, providing average values for the different cost components (investment, labor, maintenance, membrane renewal, etc.). The IAEA developed the DEEP software for the cost evaluation of thermal and RO desalination plants combined with power plants [36]. Nevertheless the purpose of these studies was not to model the RO process, which remained undefined. The detailed cost evaluation of a RO process configuration was made possible in the $\mathrm{WTCost}^{\odot}$ software developed by the Bureau of Reclamation of US Department of Interior [37]. The software used a bottom-up approach which consisted in evaluating at first the cost of each unitary plant equipment (membrane, pressure vessel, pumps) before calculating the plant capital and operating costs as the sum of the equipment costs. This method provided the most accurate cost estimation but unfortunately the cost models of each equipment were not detailed. For optimization purpose, Malek and Hawlader developed a cost evaluation method for multi-staged hollow fiber membrane configurations, which combined a top-down statistical approach for pretreatment, maintenance, labor costs and a bottom-up evaluation for RO process investment costs and power cost [15]. Several papers used this method for the cost optimization of hollow fiber membrane configurations $[15,19,21]$. However this evaluation was specific of the hollow fiber permeator and was furthermore based on statistics from 1996. The cost analysis method presented in this paper enlarges this evaluation to spiral-wound PVs and actualize the cost models with data from recent plants.

\subsubsection{Capital cost}

The capital cost for intake pumping and pretreatment $\left(\mathrm{CC}_{\mathrm{SWIP}}\right)$, for the high pressure pumps
$\left(\mathrm{CC}_{\mathrm{HP}}\right)$ and for the pressure exchangers $\left(\mathrm{CC}_{\mathrm{PX}}\right)$ are estimated using the cost models from Malek [15]. The piping investment cost $\left(\mathrm{CC}_{\text {pipes }}\right)$ is estimated using the pipe cost model from Chauvel [38]. The capital cost for post-treatment is considered to be negligible in comparison with RO process capital costs [35].

The investment cost for RO membranes $\left(\mathrm{CC}_{\mathrm{Mbne}}\right)$ and for the pressure vessels $\left(\mathrm{CC}_{\mathrm{PV}}\right)$ is calculated using the formula from Chauvel [38]:

$\mathrm{CC}_{\mathrm{E}}=f_{\mathrm{E}} \cdot p_{\mathrm{E}} \cdot \mathrm{nb}_{\mathrm{E}}$

with E equipment (membranes or PVs), $\mathrm{CC}_{\mathrm{E}}$ the investment cost for the equipments $\mathrm{E}$ in the RO process, $p_{\mathrm{E}}$ - the unitary equipment base price, $f_{\mathrm{E}}$ - the equipment corrective factor between base price and installed cost, $\mathrm{nb}_{\mathrm{E}}$ - the total number of equipments $\mathrm{E}$ in the process configuration.

The unitary membrane base price $p_{\text {Mbne }}$ is defined in the membrane database. The unitary PV base price $p_{\mathrm{PV}}$ is approximated at $1000 \$$ using market estimations [21].

The corrective factors $f_{\mathrm{E}}$ for membranes and pressure-vessels are unfortunately not defined by Chauvel [38]. In a first approach, they will be set at 1 in accordance with Malek et al. [15] and Lu et al. [21].

The investment cost for plant equipments $\left(\mathrm{CC}_{\text {equip }}\right)$ in $\$$ is equal to

$$
\begin{aligned}
\mathrm{CC}_{\text {equip }}= & \mathrm{CC}_{\mathrm{SWIP}}+\mathrm{CC}_{\mathrm{HP}}+\mathrm{CC}_{\mathrm{PX}}+\mathrm{CC}_{\text {pipe }} \\
& +\mathrm{CC}_{\text {inst }}(\mathrm{Mbne})+\mathrm{CC}_{\text {inst }}(\mathrm{PV})
\end{aligned}
$$

The total capital cost (TCC) is composed of the direct capital cost (DCC) and the indirect capital cost (ICC). The direct capital cost is the sum of the cost for plant equipments $\left(\mathrm{CC}_{\text {equip }}\right)$ and the cost for site development $\left(\mathrm{CC}_{\text {site }}\right)$, which is set at $10 \%$ of $\left(\mathrm{CC}_{\text {equip }}\right)$ [15]. The indirect capital cost (ICC) is set at $27 \%$ of the direct capital cost (DCC) [15]. 
The annualized capital cost (ACC) in \$/year is calculated using Chauvel [21]:

$$
\mathrm{ACC}=(\mathrm{TCC}) \cdot \frac{i \cdot(1+i)^{n_{\mathrm{LT}, \text { plant }}}}{(1+i)^{n_{\mathrm{LT}, \text { plant }}}-1}
$$

with $i$ the interest rate set at $5 \%, n_{\mathrm{LT} \text {,plant }}$ the plant lifetime set at 25 years.

This corresponds to a capital charge rate of $7.1 \%$.

\subsubsection{Operating cost and total water price}

The annual potable water production is based on the daily potable water production of the plant $\dot{M}_{\text {plant }}$ in $\mathrm{m}^{3} /$ day with a load factor $L_{\text {plant }}=$ $85 \%$. The annual power cost $\left(\mathrm{OC}_{\text {power }}\right)$ is calculated

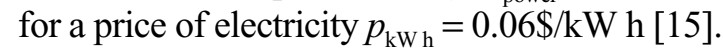

The annual $\mathrm{O} \& \mathrm{M} \operatorname{cost}\left(\mathrm{OC}_{\mathrm{O} \& \mathrm{M}}\right)$ is considered to be the sum of

- the annual labor cost $\left(\mathrm{OC}_{\text {Labor }}\right)$ set at $0.01 \$ / \mathrm{m}^{3}$ using data from Dreyzin [34],

- the annual maintenance cost $\left(\mathrm{OC}_{\mathrm{Mtnce}}\right)$ set at $0.01 \$ / \mathrm{m}^{3}$ of potable water [34],

- the annual chemical cost $\left(\mathrm{OC}_{\text {chmcal }}\right)$ set at $0.04 \$ / \mathrm{m}^{3}$ of potable water [34],

- the annual insurance cost $\left(\mathrm{OC}_{\text {insree }}\right)$ set at $0.5 \%$ of the total capital cost [38].

The annual membrane renewal cost $\left(\mathrm{OC}_{\mathrm{Mbne}}\right)$ is calculated using the membranes based price for a membrane lifetime $n_{\mathrm{LT}, \mathrm{Mbne}}=5$ years:

$$
\mathrm{OC}_{\mathrm{Mbne}}=\frac{p_{\mathrm{Mbne}} \cdot \mathrm{nb}_{\mathrm{Mbne}}}{n_{\mathrm{LT}, \mathrm{Mbne}}}
$$

The operating cost (OC) is calculated in \$/year with

$$
\mathrm{OC}=\mathrm{OC}_{\text {power }}+\mathrm{OC}_{\mathrm{O \& M}}+\mathrm{OC}_{\mathrm{Mbne}}
$$

The total water price (TMP) in $\$ / \mathrm{m}^{3}$ of potable water is calculated with
$\mathrm{TWP}=\frac{\mathrm{ACC}+\mathrm{OC}}{\dot{M}_{\text {plant }} \cdot 365 \cdot L_{\text {plant }}}$

\subsection{Environmental impacts}

If the desalination costs have been extensively studied, less work has been conducted on the environmental impacts of desalination. Life cycle assessment (LCA) is an ISO 14040 normalized method $[39,40]$ which evaluates the environmental impacts of a process based on the life-cycle inventory (LCI) of the inputs (electricity, raw materials, chemicals) and outputs induced by the process construction, operation and decommissioning. The environmental impacts of a process are calculated as the sum of the impacts resulting from its LCI inputs and outputs. As such, the LCA method is particularly appropriate for the assessment of process specificities. Indeed each process configuration is characterized by a specific inventory and therefore by specific impacts. Raluy et al. [3] performed the LCA of a given RO desalination plant. This study showed that the electricity consumed by the desalination process was responsible for more than $90 \%$ of the total plant life cycle impacts. Further LCA studies on RO desalination plants were carried out by Friedrich and Stokes, which lead to the same conclusions $[41,42]$. In these papers, the purpose was however to compare different potable water supply alternatives on case studies using standard RO process configurations. In order to use the LCA as performance indicator for optimization, the LCI ought to account for the characteristics of the RO process configuration.

For a given local context (feedwater salinity, type of electricity supply, local water resources), the modeling of the LCI as a function of the RO process configuration was performed. Process data inventory for chemicals and electricity production were taken from the Ecoinvent database [44] and the IMPACT 2002+ method [45] was used for impact assessment. Within the LCA scope, the electricity consumption of the RO process was shown to be responsible for 
more than $90 \%$ of the impacts of the RO desalination plant. The impacts of the plant construction and decommissioning phases as well as the impacts of membrane renewal were found to be negligible in comparison with the electricity consumption impacts. The impacts associated to RO process electricity consumption were generated off-site by electricity production. The production of electricity may indeed use fossil fuels which combustion emits $\mathrm{CO}_{2}$, thus leading to high potential impacts on climate change. Between electricity supply from renewable sources, nuclear energy or coal power plants, electricity production impacts may be multiplied by as much as 10 . The local electricity production mix and the value of electric consumption at plant had therefore a tremendous influence on the impacts of desalination processes $[46,47]$. In accordance with the present work, the reduction of energy consumption through $\mathrm{RO}$ process optimization appeared to be the first action to be carried out for impact reduction. A "green" electricity supply (e.g. from renewable sources) was also identified as a major solution for desalination impact reduction.

To date, the LCA methods are however not sufficiently developed to assess the impacts resulting from liquid discharges into water bodies $[48,49]$. Lattemann and Höpner described qualitatively the potential impacts resulting from concentrate discharges [4] but even on realcase studies, these impacts (e.g. ecotoxicity and eutrophication) are not well quantified. If the amplitude of the impacts cannot be assessed, they will nevertheless depend on the discharged flow rates and therefore on the total water recovery rate of the desalination plant.

Resulting from this impact assessment, the total recovery rate and the electricity consumption appear as representative values in order to measure the environmental performances of RO desalination plants. Although they do not represent a designated impact, they will therefore be used as environmental performances indicators.

\section{Multi-objective optimization procedure}

The optimization of the RO process defines a mixed integer nonlinear programming (MINLP) problem [16,50], which decision variables concern:

- The RO process layout (membrane type, number of modules per pressure vessel, number of stages, number of passes and piping network).

- The operating conditions (pressure vessel recovery rate, membrane average permeate flux ...).

Within the technical limits of good practice of each decision variable, the optimization problem consists in identifying the sets of decision variables corresponding to RO process configurations with the best performances for the selected objectives. The optimal values of these decision variables are obtained by solving a multi-objective optimization (MOO) problem following the procedure presented in Fig. 1. Each set of decision variables defines a specific RO process configuration which performances are evaluated for technical, environmental (total recovery rate, energy consumption) and economical criteria (investment and operating costs). These performance indicators are the objective functions of the MOO problem, which is solved using an evolutionary algorithm developed by Leyland [51]. This MOO procedure allows to optimize the RO process simultaneously for diverse objectives without having to rank these objectives or to define an allocation between them $[52,53]$. For two conflicting objectives such as the minimization of environmental impacts and the minimization of economical costs, the MOO results are not restrained to one unique solution but instead constitute a set of optimal solutions illustrating the trade-off between these objectives. These solutions define the so-called Pareto frontier (represented for example in Fig. 6), which should be interpreted as a materialization of technical, 


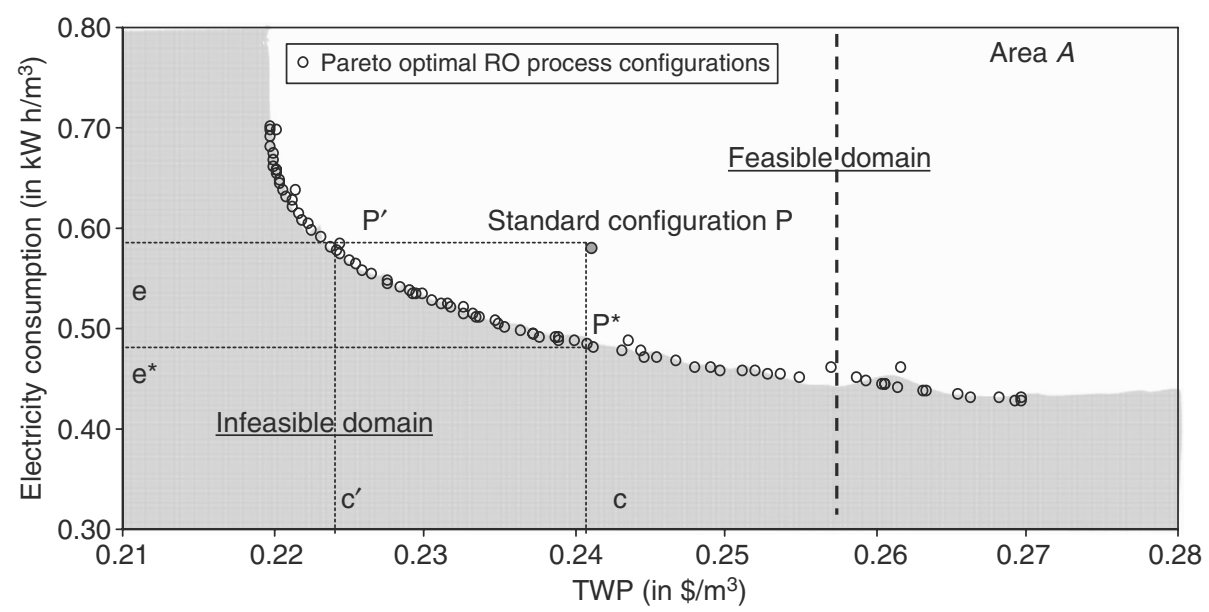

Fig. 6. Optimized RO process configurations for $C_{\mathrm{WR}}=3 \mathrm{~g} / \mathrm{L}$ and $C_{\max }=0.3 \mathrm{~g} / \mathrm{L}$.

economical or environmental constraints applied to the RO process design.

\section{Application to a case study}

The studied project has the following specifications:

- Potable water

- Daily production capacity $\dot{M}_{\text {plant }}: 35,000$ $\mathrm{m}^{3} / \mathrm{d}$

- Maximum permeate salinity $C_{\max }: 0.3 \mathrm{~g} / \mathrm{L}$

- Water resource

- Salinity $C_{\mathrm{WR}}: 3 \mathrm{~g} / \mathrm{L}$

- Membrane fouling factor FF: $85 \%$

- Temperature $T: 20^{\circ} \mathrm{C}$

- No flow limits on water intake and water discharge

- Objectives

- Minimize the total water price TWP in $\$ / \mathrm{m}^{3}$ of potable water

- Minimize the electrical consumption in $\mathrm{kW} \mathrm{h} / \mathrm{m}^{3}$ of potable water

The number of membranes per PV varies between 3 and 8 . The flux and recovery rate of the generated PVs may vary within the feasibility limits. The connection network is defined by the superstructure optimization with no other constraints than the project specifications and the PV tolerances. In this project, pressure exchangers are not considered for brackish water reverse osmosis (BWRO) processes.

\subsection{Pareto curve of optimal solutions}

The Pareto curve of the optimized RO process configurations is displayed in Fig. 6.

For the sake of comparison, a standard 2:1 two-staged RO process configuration has been located in Fig. 6 (configuration P). The first stage and the second stage of configuration P use 6 BW30LE-440 membrane modules PVs with a water recovery rate of $50 \%$ and an average membrane permeate flux of $20 \mathrm{~L} \mathrm{~m}^{-2} \mathrm{~h}^{-1}$ (or LMH). A booster pump is installed for the second stage. The configuration $\mathrm{P}$ with performances (c, e) is shown to be suboptimal because the configuration $\mathrm{P}^{\prime}$ requires a lower cost $\mathrm{c}^{\prime}$ for the same electricity consumption e while the configuration $\mathrm{P}^{*}$ has an electricity consumption $\mathrm{e}^{*}$ lower than e for the same cost $\mathrm{c}$ (Table 2). Regarding the project specifications, the RO process configuration $\mathrm{P}^{\prime}$ and $\mathrm{P}^{*}$ are Pareto optimal because

- for any cost c, it is technically infeasible to achieve lower electricity consumption than $\mathrm{e}^{*}$; 
Table 2

Characteristics of $\mathrm{RO}$ process configurations $\mathrm{P}, \mathrm{P}^{\prime}$ and $\mathrm{P}^{*}$

\begin{tabular}{|c|c|c|c|c|c|c|}
\hline RO process configurations & \multicolumn{2}{|l|}{$\mathrm{P}$} & \multicolumn{2}{|l|}{$\mathrm{P}^{*}$} & \multicolumn{2}{|l|}{$\mathrm{P}^{\prime}$} \\
\hline Total water recovery rate, $\%$ & 74 & & 81 & & 82 & \\
\hline Total electricity consumption, $\mathrm{kW} \mathrm{h} / \mathrm{m}^{3}$ & 0.59 & & 0.48 & & 0.59 & \\
\hline Investment cost, million $\$ /\left(\mathrm{m}^{3} /\right.$ day $)$ & 455 & & 438 & & 402 & \\
\hline Annualized investment cost, $\$$ cents $/ \mathrm{m}^{3}$ & 10 & & 10 & & 9 & \\
\hline Operating cost, $\$$ cents $/ \mathrm{m}^{3}$ & 14 & & 14 & & 13 & \\
\hline Power cost, $\$$ cents $/ \mathrm{m}^{3}$ & 3.6 & & 2.9 & & 3.7 & \\
\hline O\&M costs, $\$$ cents $/ \mathrm{m}^{3}$ & 7.3 & & 6.5 & & 6.5 & \\
\hline Membrane renewal, $\$$ cents $/ \mathrm{m}^{3}$ & 3.0 & & 4.3 & & 2.7 & \\
\hline Total annual cost, $\$$ cents $/ \mathrm{m}^{3}$ & 24.0 & & 24.0 & & 22.3 & \\
\hline Stages & 1st stage & 2nd stage & 1st stage & 2nd stage & 1st stage & 2nd stage \\
\hline Number of pressure vessels, - & 191 & 96 & 278 & 89 & 186 & 60 \\
\hline Number of membranes per PV, - & 6 & 6 & 7 & 7 & 7 & 7 \\
\hline Module recovery rate, $\%$ & 50 & 50 & 64 & 49 & 64 & 50 \\
\hline Average permeate flow by PV, LMH & 20 & 20 & 14 & 12 & 21 & 19 \\
\hline First membrane permeate flow, LMH & 25 & 28 & 20.7 & 22.5 & 28 & 31 \\
\hline Average TMP, Bar & 10.4 & 13.7 & 9.5 & 12.6 & 11.3 & 17.2 \\
\hline Module feedwater salinity, $\mathrm{g} / \mathrm{L}$ & 3 & 6 & 3 & 8.6 & 3 & 8.6 \\
\hline Module permeate salinity, $\mathrm{g} / \mathrm{L}$ & 0.1 & 0.2 & 0.2 & 0.5 & 0.1 & 0.3 \\
\hline Module concentrate salinity, g/L & 6 & 12.1 & 8.6 & 17.2 & 8.6 & 17.6 \\
\hline
\end{tabular}

- for any electricity consumption e, it is technically infeasible to achieve lower cost than $\mathrm{c}^{\prime}$.

\subsection{Process layout and recovery rate}

For the given project specifications, the optimal process configurations achieve to produce potable water with a TWP between 0.22 and
$0.27 \$ / \mathrm{m}^{3}$ and an electricity consumption between 0.4 and $0.7 \mathrm{~kW} \mathrm{~h} / \mathrm{m}^{3}$. They all used a two-staged process layout with BW30LE-440 membrane PVs and an inter-stage booster pump (Fig. 7). This two-staged layout is therefore proved to minimize simultaneously the electricity consumption and the TWP. Indeed, it is particularly suitable for BWRO because the 2nd stage operation

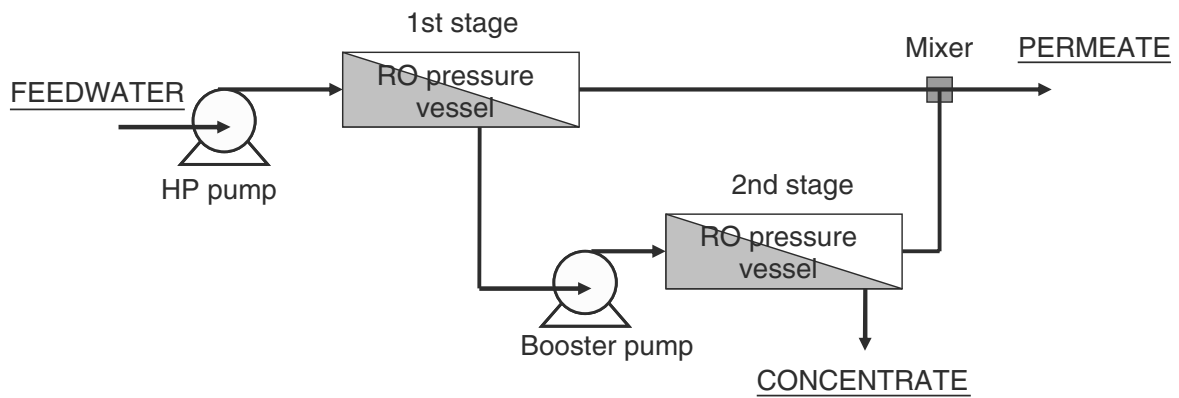

Fig. 7. Optimal RO process flowsheet. 
is favored by the remaining pressure of the 1 st concentrate, thus allowing to increase the recovery rate and to reduce the pumping needs. The installation of inter-stage booster pumps also appears to be a "win-win" option from an economic and environmental point of view. With a booster pump, the 2nd stage can be operated in nominal hydraulic conditions, thus leading to a smaller installed membrane area and to a higher total recovery rate, therefore reducing the electricity consumption and the investment costs.

When analyzing the solutions, it appears that there are two groups of solutions. Solutions identified by area $\mathrm{A}$ in the following figures use pressure vessels with 4 membrane modules for the 1st stage and 7 membrane modules for the 2nd stage while the other configurations use 7 membranes PVs for both first and second stage. These latter configurations are operated with an optimal recovery rate of $82 \%$, with a recovery rate of $64 \%$ for the first stage and a recovery rate of $50 \%$ for the second stage (Fig. 8). As an example of these configurations, the operating conditions of $\mathrm{P}^{\prime}$ are detailed in Table 3.

The optimal recovery rate slightly decreases from 84 to $75 \%$ when searching for lower electricity consumption. However this leads to higher costs due to the total membrane area increase. The optimal recovery rate depends on economical criteria such as electricity and membrane prices as well as technical criteria such as feedwater salinity, membrane permeability or high pressure pumps efficiency. If not adapted to the local context, fixed water recovery rate will lead to inefficient configurations such as the configuration P.

The configurations in area $A$ represent a different technological alternative adapted to low energy processes. The choice is made to lower the role of the first stage with shorter 4 membranes PVs and a smaller water recovery rate of $45 \%$. These configurations rely on a more important second stage, which benefits from the residual concentrate pressure to achieve a high recovery rate of $55 \%$ with low electricity consumption. However the number of PVs in the 2nd stage more than doubles in comparison with the other configurations and thus leads to high investment and membrane renewal costs.

The optimal ratio between the installed membrane area in the 1st stage and in the 2 nd stage is highly correlated to the opposite of the 1st stage water recovery rate (Fig. 9). In this project, it stays below $50 \%$ due to the high 1 st stage recovery rate (over $50 \%$ ), except for the configurations in area $A$ whose 2 nd stage requires more

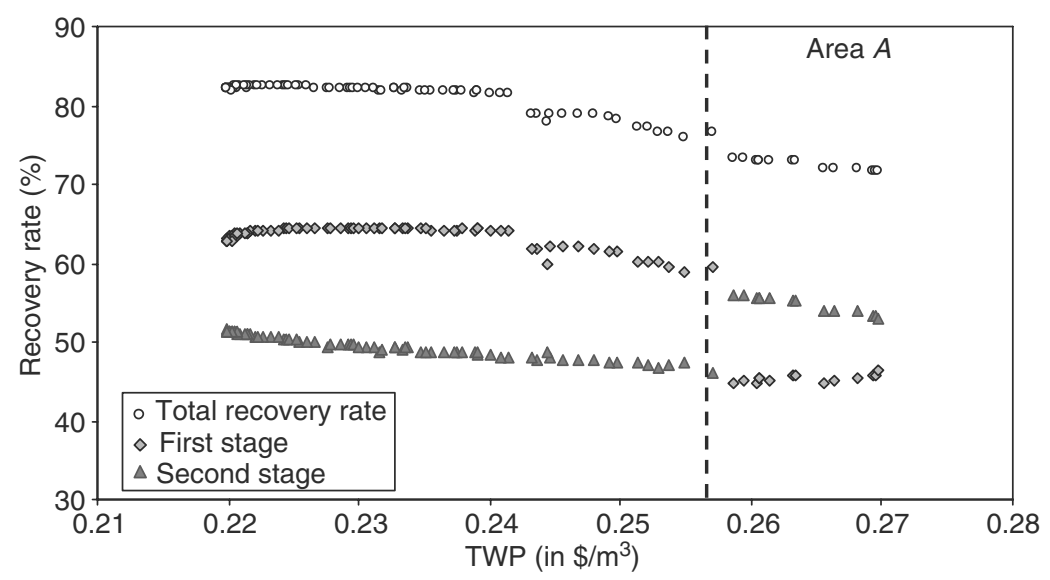

Fig. 8. Recovery rate of the optimized RO process configurations. 
Table 3

Operating conditions for the 1st and 2nd stages of configuration $\mathrm{P}^{\prime}$

\begin{tabular}{|c|c|c|c|c|c|c|c|}
\hline Membrane number $k$ & $r_{k}(\%)$ & $J_{\mathrm{w}}^{k}(\mathrm{LMH})$ & $\dot{M}_{\mathrm{f}}^{k}\left(\mathrm{~m}^{3} / \mathrm{h}\right)$ & $C_{\mathrm{p}}^{k}(\mathrm{~g} / \mathrm{L})$ & $C_{\mathrm{f}}^{k}(\mathrm{~g} / \mathrm{L})$ & $\Delta P^{k}$ (bar) & $\Delta \pi^{k}$ (bar) \\
\hline \multicolumn{8}{|l|}{ First stage } \\
\hline 1 & 12.2 & 27.9 & 9.3 & 0.06 & 3.0 & 11.4 & 2.7 \\
\hline 2 & 13.0 & 26.1 & 8.2 & 0.07 & 3.4 & 11.2 & 3.1 \\
\hline 3 & 13.8 & 24.1 & 7.1 & 0.09 & 3.9 & 11.0 & 3.6 \\
\hline 4 & 14.4 & 21.6 & 6.1 & 0.11 & 4.6 & 10.8 & 4.2 \\
\hline 5 & 14.6 & 18.8 & 5.3 & 0.15 & 5.4 & 10.7 & 4.9 \\
\hline 6 & 14.3 & 15.7 & 4.5 & 0.21 & 6.3 & 10.5 & 5.8 \\
\hline 7 & 13.0 & 12.3 & 3.9 & 0.31 & 7.4 & 10.3 & 6.8 \\
\hline \multicolumn{8}{|l|}{ Second stage } \\
\hline 1 & 12.0 & 30.9 & 10.6 & 0.15 & 8.6 & 17.2 & 7.6 \\
\hline 2 & 11.9 & 27.0 & 9.3 & 0.19 & 9.7 & 17.0 & 8.8 \\
\hline 3 & 11.3 & 22.7 & 8.2 & 0.26 & 11.0 & 16.8 & 9.9 \\
\hline 4 & 10.3 & 18.3 & 7.3 & 0.36 & 12.5 & 16.6 & 11.2 \\
\hline 5 & 8.8 & 14.0 & 6.5 & 0.52 & 13.9 & 16.4 & 12.4 \\
\hline 6 & 7.1 & 10.3 & 5.9 & 0.77 & 15.3 & 16.2 & 13.5 \\
\hline 7 & 5.4 & 7.3 & 5.5 & 1.15 & 16.6 & 16.0 & 14.4 \\
\hline
\end{tabular}

membranes than the 1st stage. The traditional $2: 1$ configuration appears to be adequate for a 1 st stage recovery rate equal to $50 \%$ but may be inappropriate for other recovery rates. For economical and energy efficiency, the number of PVs per stage ought therefore to be adapted to the local context.

Considering the water recovery rate as an environmental indicator for water resource protection and liquid discharges reduction, this analysis shows that the economically and energetically optimal recovery rate is already higher than the recovery rate used in standard designs. However if high recovery rate can be achieved for a minimal cost, there is obviously a trade-off between electricity consumption and total recovery rate, i.e. between the discharged flow rates and the green house gases emissions. Indeed high recovery

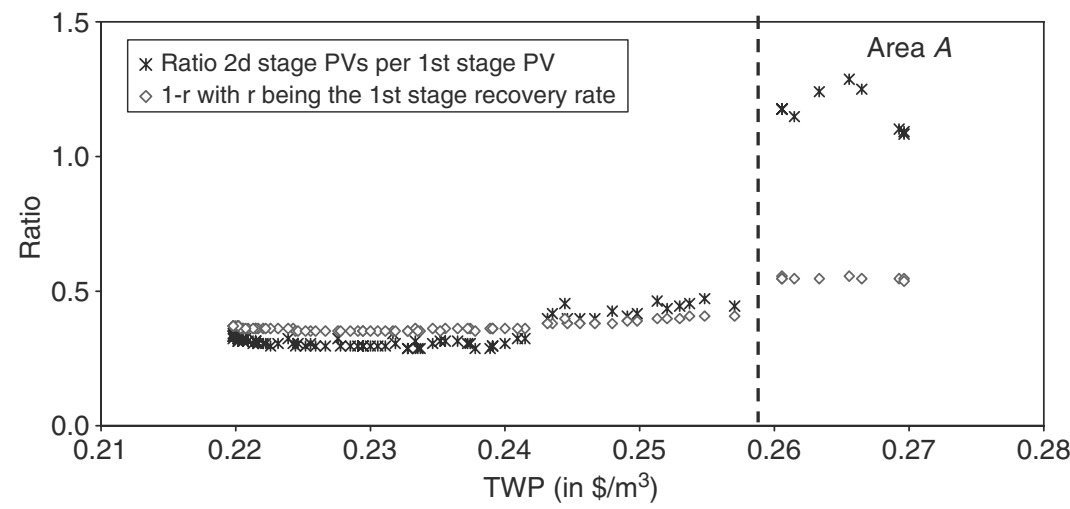

Fig. 9. Optimal ratio between 1st and 2nd stage membrane area. 
rates generate concentrate with high osmotic pressure which ought to be counterbalanced by applying higher transmembrane pressure. This trade-off ought to be kept in mind while minimizing desalination environmental impacts.

The multi-objective optimization was carried out with the same project specifications for 3 objectives (total recovery rate, electricity consumption and TWP). Configurations with recovery rates beyond $85 \%$ were identified but their economical and energetic performances were degraded (higher average electrical consumption at $0.7 \mathrm{~kW} \mathrm{~h} / \mathrm{m}^{3}$ and higher average costs at $0.25 \$ / \mathrm{m}^{3}$ ). It seems therefore reasonable to stay at the optimal recovery rate of $81 \%$ rather than to increase the recovery rate beyond this limit and generating high economical and energetic losses.

\subsection{Membrane permeate flux}

The two-staged RO process layout and the water recovery rate are found to be optimal for both economical and environmental objectives. On the contrary, the analysis of the Pareto frontier shows that the choice of the membrane permeate flux constitutes a trade-off between these objectives. Indeed the costs and the electricity consumption vary differently with the permeate flux. In order to illustrate this dependency, the average membrane permeate flux and the TMP applied on both stages of the optimal configurations are represented as a function of the TWP (Fig. 10).

With respect to Eq. (4), the low feedwater salinity of the first stage allows to operate the $1 \mathrm{st}$ stage with high flux and low pressure whereas the increased salinity of the 2 nd stage feedwater requires to operate the 2 nd stage with a lower flux and a higher pressure. Both stages vary similarly with high (respectively low) permeate flux applied pressure for low (respectively high) TWP.

In order to analyze the influence of the operating conditions on the cost breakdown, the cost components constituting the TWP are represented as a function of the permeate flux in Fig. 11. These points out that the fixed charge and the O\&M cost remain approximately constant at 10 and 6.5 cents $/ \mathrm{m}^{3}$ for the optimal configurations. The cost variation between the generated configurations results from the membrane renewal and power costs which represent the trade-off between energy consumption and costs. When permeate flux increases, the electricity consumption and the power cost increase. But flux increase allows simultaneously to decrease the installed membrane area and therefore to reduce

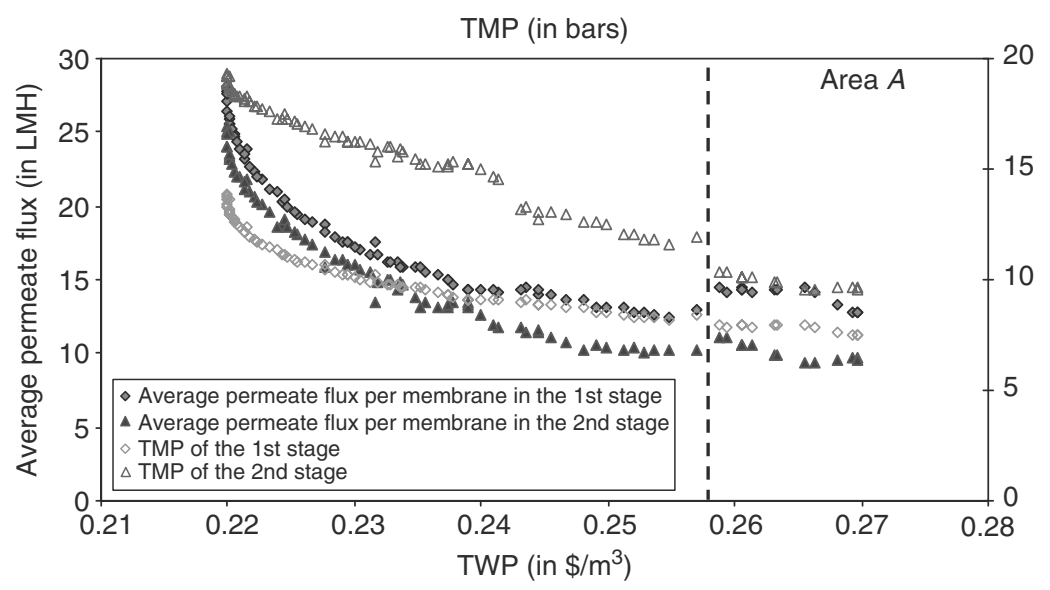

Fig. 10. Permeate flux and TMP of the optimal configurations. 


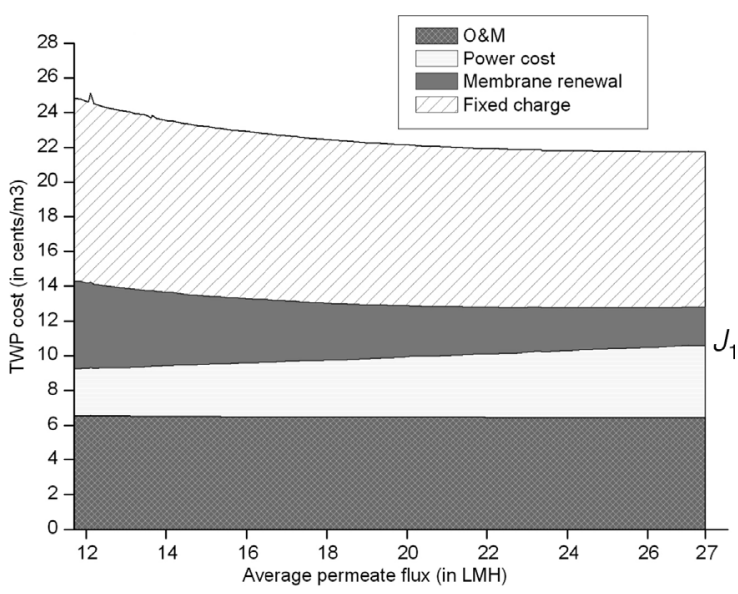

Fig. 11. TWP of optimal solutions as a function of average membrane permeate flux.

the membrane renewal cost. In this case study, it is cost efficient to operate the RO process with high permeate fluxes between 25 and $27 \mathrm{LMH}$. This means that the reduction of the membrane renewal cost due to high flux operation is always higher than the cost increase of electricity consumption. Achieving the minimum electricity consumption is therefore economically inefficient because it leads a membrane renewal cost higher than the power cost reduction.

No optimal configuration has been generated with fluxes higher than $27 \mathrm{LMH}$. Considering that the TWP decreases with the flux, this flux therefore allows to reach the lowest feasible TWP for the project specifications. This optimal value may also be calculated by comparing the marginal rates of membrane renewal cost and power cost per flux unit. The electricity consumption increase proportionally with the flux, so that the marginal power cost is shown to be constant as a function of the flux. The membrane renewal cost is calculated using the total membrane area, which is proportional to the flux inverse. Therefore the marginal gain on membrane renewal decreases with the flux, as stated in Fig. 11. Beyond $J_{1}=27 \mathrm{LMH}$, the marginal difference (marginal power cost marginal gain on membrane renewal) is positive and results in TWP increase. Below $J_{1}$, the marginal difference is negative and results in TWP decrease. For $J_{1}=27 \mathrm{LMH}$, the TWP minimal value is reached because the marginal gain on membrane renewal is equal to the marginal power cost.

For the generated configurations, a flux increase from 10 to $20 \mathrm{LMH}$ leads to a TWP reduction of approximately 4 cents $/ \mathrm{m}^{3}$ while increasing the electricity consumption of approximately $0.15 \mathrm{~kW} \mathrm{~h} / \mathrm{m}^{3}$. From 20 to $27 \mathrm{LMH}$, the cost reduction is limited to 0.5 cents $/ \mathrm{m}^{3}$ for an electricity consumption increase of $0.1 \mathrm{~kW} \mathrm{~h} / \mathrm{m}^{3}$. Considering that the flux increase from 20 to $27 \mathrm{LMH}$ results in a small cost benefit for a still relevant increase of electricity consumption, it appears effective from an environmental point of view to keep an average permeate flux of $20 \mathrm{LMH}$.

The analysis shows that design choices such as the applied permeate flux result in completely different performances. For the project specifications, economically optimal configurations used a two-staged design with a membrane permeate flux of $27 \mathrm{LMH}$ while energetically optimal configurations used a two-staged design with low flux and a lower water recovery rate. These choices were however performed in given economical and technical conditions. These conditions may vary after the plant building and require to adapt the operating choices.

\section{Optimal designs as a function of local context}

The developed method allows to optimize the RO process for different constraints and local parameters. In order to illustrate the flexibility of the design procedure, 2 other projects are analyzed. They have the same characteristics than the studied project (production capacity, permeate maximal salinity) except for the feedwater salinity 


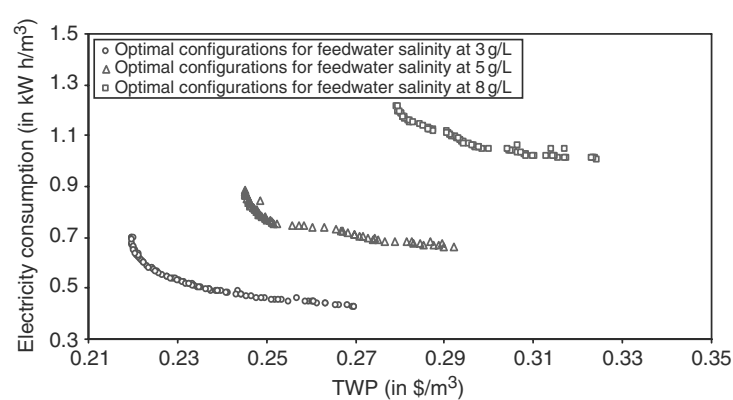

Fig. 12. Optimal RO process configurations for a feedwater salinity of 3,5 and $8 \mathrm{~g} / \mathrm{L}$.

equal to $5 \mathrm{~g} / \mathrm{L}$ for the second project and to $8 \mathrm{~g} / \mathrm{L}$ for the third project. The generated optimal configurations are represented in Fig. 12 with the optimal configurations for $3 \mathrm{~g} / \mathrm{L}$. The production of potable water from feedwater at a salinity of $5 \mathrm{~g} / \mathrm{L}$ is achieved with a minimal cost of $0.25 \$ / \mathrm{m}^{3}$ and an electricity consumption of $0.8 \mathrm{~kW} \mathrm{~h} / \mathrm{m}^{3}$. For a salinity of $8 \mathrm{~g} / \mathrm{L}$, a minimal cost of $0.28 \$ / \mathrm{m}^{3}$ is reached with an electricity consumption of $1.2 \mathrm{~kW} \mathrm{~h} / \mathrm{m}^{3}$. Potable water production is performed at the same price from sources with different salinity (for example with a TWP of 0.26 cents $/ \mathrm{m}^{3}$ ) by optimal solutions being either cost-optimal solutions at $5 \mathrm{~g} / \mathrm{L}$ or environmental friendly solutions at $3 \mathrm{~g} / \mathrm{L}$. These configurations are based on a two-staged layout with an optimal recovery rate of $75 \%$ for $5 \mathrm{~g} / \mathrm{L}$ and of $70 \%$ for $8 \mathrm{~g} / \mathrm{L}$. The optimal number of membranes per PV in the first stage is equal to 6 for $5 \mathrm{~g} / \mathrm{L}$ and varies between 5 and 7 for $8 \mathrm{~g} / \mathrm{L}$. Rather than detailing these new configurations, this analysis proves that specific design choices cannot be fixed as a rule of thumb for RO design but ought to be reviewed, when starting a new project in a different economical and technological context.

\section{Conclusions}

An advanced RO process design method has been developed, which allows to identify the best process $\mathrm{RO}$ process configurations for given project specifications. The RO process configurations are synthesized using a flexible superstructure and realistic spiral-wound membrane PV models for the representation of the reverse osmosis network. Their performances are evaluated by updated cost models and their environmental impacts are assessed with the electricity consumption and the total recovery rate being identified as representative values of RO process environmental performances. These performances indicators are used to optimize the RO process within a economical and environmental approach.

A case study is presented for which the optimal layout and operating conditions are assessed. The optimal recovery rate is characterized as a function of the local context (e.g. feedwater salinity). The trade-off between environmental and economical objectives is identified by the definition of the permeate flux. For high permeate flux, low total costs are reached but electricity consumption and desalination environmental impacts are high. Low permeate flux allows to achieve lower electricity consumption but ought to be compensated by larger membrane area and higher costs. A second trade-off is identified between the two main impacts of desalination (electricity consumption and brine discharges). Indeed brine discharge can be reduced only with higher electricity consumption.

The cost breakdown of these optimal configurations shows that the investment cost and the O\&M cost remain approximately constant for the optimal configurations while cost variations result rather from the influence of operating conditions on power cost and membrane renewal cost.

At last, the multi-objective optimization procedure is applied to other RO projects, in order to illustrate the flexibility of the design method. The solutions generated by the developed RO design method form a panel of various process alternatives adapted to the local context, from cost-optimal configurations to environmental 
friendly configurations, among which technology developers can choose according to their own weighting criteria and constraints.

\section{Acknowledgements}

The authors acknowledge the support of the French National Association for Technical Research (CIFRE Convention 956/2004) and the participation of M. Pontié (GAP — University of Angers, France).

\section{Nomenclature}

$T \quad$ water temperature (K)

$P \quad$ pressure $(\mathrm{Pa})$

FF membrane fouling factor (\%)

$\dot{M} \quad$ mass flow rate $\left(\mathrm{kg} \cdot \mathrm{s}^{-1}\right)$

$J_{\mathrm{w}} \quad$ water mass flux through the membrane $\left(\mathrm{kg} \cdot \mathrm{m}^{-2} \cdot \mathrm{s}^{-1}\right)$

$J_{\mathrm{s}} \quad$ salts mass flux through the membrane $\left(\mathrm{kg} \cdot \mathrm{m}^{-2} \cdot \mathrm{s}^{-1}\right)$

$C \quad$ salts mass concentration ( $\mathrm{kg}$ of salts per $\mathrm{kg}$ of water)

$R \quad$ universal gases constant $\left(\mathrm{J} \cdot \mathrm{mol}^{-1} \cdot \mathrm{K}^{-1}\right)$

$\mathrm{R} \quad$ rejection rate $(\%)$

$r \quad$ membrane water recovery rate (\%)

$\bar{r} \quad$ water recovery rate of the pressure vessel $(\%)$

$S_{\mathrm{M}} \quad$ membrane active area $\left(\mathrm{m}^{2}\right)$

$\Delta P \quad$ applied transmembrane pressure $(\mathrm{Pa})$

$\Delta \pi \quad$ transmembrane osmotic pressure $(\mathrm{Pa})$

$\Delta p_{\text {drop }} \quad$ transmembrane pressure drop $(\mathrm{Pa})$

$A$ membrane pure water permeability at $T$ and FF $\left(\mathrm{kg} \cdot \mathrm{m}^{-2} \cdot \mathrm{s}^{-1} \cdot \mathrm{Pa}^{-1}\right)$

$A_{\text {ref }}(\Delta \pi)$ reference permeability at $T_{0}=298 \mathrm{~K}$ without fouling $\left(\mathrm{kg} \cdot \mathrm{m}^{-2} \cdot \mathrm{s}^{-1} \cdot \mathrm{Pa}^{-1}\right)$

TCF temperature correction factor at $T(\%)$

$B \quad$ membrane salts permeability $\left(\mathrm{kg} \cdot \mathrm{m}^{-2} \cdot \mathrm{s}^{-1}\right)$

$n_{\mathrm{e}} \quad$ number of membrane modules in a PV (-)

Mbne type of membrane module (-)

$n_{\mathrm{LT} \text {,plant }}$ potable water production plant lifetime (years)

$\begin{array}{ll}n_{\mathrm{LT}, \mathrm{Mbne}} & \begin{array}{l}\text { nominal membrane lifetime (years) } \\ J_{\mathrm{w}, \mathrm{max}}\end{array} \\ \begin{array}{l}\text { maximum membrane permeate mass } \\ \text { flux }\left(\mathrm{kg} \cdot \mathrm{m}^{-2} \cdot \mathrm{s}^{-1}\right)\end{array} \\ J_{\mathrm{w}, \mathrm{nom}} & \begin{array}{l}\text { nominal } \mathrm{membrane} \text { permeate mass } \\ \text { flux }\left(\mathrm{kg} \cdot \mathrm{m}^{-2} \cdot \mathrm{s}^{-1}\right)\end{array} \\ \mathrm{CC} & \begin{array}{l}\text { capital cost }(\$) \\ \text { unitary base price }(\$)\end{array} \\ p & \begin{array}{l}\text { plant daily potable water production } \\ \left(\mathrm{m}^{3} / \text { day }\right)\end{array} \\ \dot{M}_{\text {plant }} & \text { plant average load factor }(\%) \\ L_{\text {plant }} & \begin{array}{l}\text { annualized capital cost }(\$ / \text { year }) \\ \text { ACC }\end{array} \\ \text { OC } & \text { annual operating cost }(\$ / \text { year }) \\ \text { TWP } & \text { total water price }\left(\$ / \mathrm{m}^{3}\right)\end{array}$

\section{Subscript}

f feedwater

$\mathrm{p} \quad$ permeate

c concentrate

w wall

\section{Indices}

$k \quad$ membrane $k$ in the pressure vessel

\section{References}

[1] World Water Assessment Programme, The United Nations World Water Development Report "Water for People, Water for Life", UNESCO, 2003.

[2] C. Gasson, Desalination Markets 2005-2015: A Global Assessment and Forecast, Global Water Intelligence, 2004.

[3] R.G. Raluy, et al., Life cycle assessment of water production technologies. Part 2: Reverse osmosis desalination versus Ebro River water transfer, Int. J. Life Cycle Assess., 10 (2004).

[4] S. Lattemann and T. Höpner, Seawater desalination: Impacts of brine and chemical discharge on the marine environment, Desalination Publications, 2004.

[5] M.M. El-Halwagi, Pollution Prevention through Process Integration: Systematic Design Tools, A. Press, 1997.

[6] H.K. Lonsdale, et al., Transport properties of cellulose acetate osmotic membranes, J. Appl. Polym. Sci., 9 (1965) 1341-1362. 
[7] S. Kimura and S. Sourirajan, Analysis of data in reverse osmosis with porous cellulose acetate membranes used, AIChE J., 13 (1967) 497-503.

[8] O. Kedem and A. Katchalsky, Thermodynamic analysis of the permeability of biological membranes to non-electrolytes, Biochim. Biophys. Acta, 27 (1958) 229-246.

[9] DOW, Design a reverse osmosis system: design equations and parameters, Technical Manual, 2006.

[10] Hydranautics, IMSDesign, Nitto Denko Corporation, 2006.

[11] F. Evangelista, Improved graphical-analytical method for the design of reverse-osmosis plants, Indus. Eng. Chem. Process Design Develop., 25 (1986) 366-375.

[12] N.M. Al-Bastaki and A. Abbas, Modeling an industrial reverse osmosis, Desalination, 126 (1999) 33-39.

[13] J.W. McCutchan and V. Goel, System analysis of a multistage tubular module reverse-osmosis plant for sea water desalination, Desalination, 14 (1974) $57-76$.

[14] W.G. Van der Meer, et al., Only two membrane modules per pressure vessel? Hydraulic optimization of spiral-wound membrane filtration plants, Desalination, 119 (1998) 57-64.

[15] A. Malek, et al., Design and economics of RO seawater desalination, Desalination, 105 (1996) 245-261.

[16] M.M. El-Halwagi, Synthesis of reverse-osmosis networks for waste reduction, Am. Inst. Chem. Eng., 38 (1992) 1185-1198.

[17] M. Fazilet, Optimization of reverse osmosis membrane networks, Ph.D. Thesis, University of New South Wales, 2000.

[18] N. Voros, et al., Optimization of reverse osmosis networks for seawater desalination, Comput. Chem. Eng., 20 (1996) 345-350.

[19] M.G. Marcovecchio, et al., Global optimal design of reverse osmosis networks for seawater desalination: modeling and algorithm, Desalination, 184 (1-3) (2005) 259-271.

[20] C. Guria, et al., Multi-objective optimization of reverse osmosis desalination units using different adaptations of the non-dominated sorting genetic algorithm (GA), Comput. Chem. Eng., 29 (2005) 1977-1995.

[21] Y.-Y. Lu, et al., Optimum design of reverse osmosis system under different feed concentration and product specification, J. Membr. Sci., 287 (2007) 219-229.

[22] K.S. Spiegler and O. Kedem, Thermodynamics of hyperfiltration (reverse osmosis): criteria for efficient membranes, Desalination, 1 (1966) 311-326.

[23] S. Kimura and S. Sourirajan, Concentration polarization effects in reverse osmosis using porous cellulose acetate membranes, Indus. Eng. Chem. Process Design Develop., 7 (1) (1968) 41-48.

[24] J.S. Taylor, et al., Simplified modelling of diffusion-controlled membrane systems, J. Water Supply: Res. Technol. - AQUA, 43 (1994) 238-245.

[25] K. Sirkar, et al., Approximate design equations for reverse osmosis desalination by spiral-wound modules, Indus. Eng. Chem. Process Design Develop., 21 (1982) 517-527.

[26] K.S. Gupta, Analytical design equations for reverse osmosis systems, Indus. Eng. Chem. Process Design Develop., 24 (1985) 1240-1244.

[27] G. Schock and A. Miquel, Mass transfer and pressure loss in spiral wound modules, Desalination, 64 (1087) 339-352.

[28] E. Wittmann, La nanofiltration dans le domaine du traitement des eaux: conditions d'application et modélisation, Université de Montpellier, 1998.

[29] H. Mehdizadeh, et al., Temperature effects on the performance of thin-film composite, aromatic polyamide membranes, Indus. Eng. Chem. Res., 28 (1989) 814-824.

[30] F. Vince, et al., Innovative design and multiobjective optimization of hybrid reverse osmosis and multi-stage flash desalination plants, CHISA, Prague, 2006.

[31] N.M. Wade, Technical and economic evaluation of distillation and reverse osmosis desalination processes, Desalination, 93 (1993) 343-363.

[32] S. Ebrahim and M. Abdel-Jawad, Economics of seawater desalination by reverse osmosis, Desalination, 94 (1994) 39-55.

[33] M.A. Darwish, et al., Technical and economical comparison between large capacity multi-stage flash and reverse osmosis desalting plants, Desalination, 72 (1989) 367-379.

[34] Y. Dreyzin, Ashkelon seawater desalination project - off-taker's self costs, supplied water costs and benefits, Desalination, 190 (2006) 104-116. 
[35] C. Sommariva, Desalination Management and Economics, Mott Mac Donald, 2004.

[36] IAEA, Desalination Economic Evaluation Program (DEEP): User's Manual, International Atomic Energy Agency, 2004.

[37] WTCost $(C)$ Model, in: Desalting Handbook for Planners, United States Department of Interior, Bureau of Reclamation, 2003 (Chapter 9).

[38] A. Chauvel, Manual of Process Economic Evaluation, TECHNIP, 2003.

[39] UNEP/SETAC, Life Cycle Approaches: the Road from Analysis to Practice, UNEP/SETAC Life Cycle Initiative, 2005.

[40] AFNOR, ISO 14040: Environmental Management - Life Cycle Assessment — Principles and framework, 2000.

[41] E. Friedrich, Environmental Life Cycle Assessment of Potable Water Production, University of Natal, South Africa, 2001.

[42] J. Stokes and A. Horvath, Life cycle energy assessment of alternative water supply systems, Int. J. Life Cycle Assess., 11 (2005) 335-343.

[43] R. Frischknecht, et al., Ecoinvent v1.1: Code of Practice, Swiss Centre for Life Cycle Inventories, 2004.

[44] S. Humbert, et al., IMPACT 2002+: User Guide, Industrial Ecology \& Life Cycle Systems Group,
Swiss Federal Institute of Technology Lausanne (EPFL), 2005.

[45] R.G. Raluy, et al., Life cycle assessment of desalination technologies integrated with energy production systems, Desalination, 167 (2004) 445-458.

[46] R.G. Raluy, et al., Life cycle assessment of desalination technologies integrated with renewable energies, Desalination, 183 (2005) 81-93.

[47] A.U. Helias, et al., Three strategies to overcome the limitations of LCA, J. Indus. Ecol., 8 (3) (2004).

[48] J. Payet, Assessing Toxic Impacts On Aquatic Ecosystems In Life Cycle Assessment, Swiss Federal School of Technology, 2004.

[49] I.E. Grossmann, MINLP Optimisation Strategies and Algorithms for Process Synthesis, Foundations of Computer-aided Process Design, 1990.

[50] G.B. Leyland, Multi-Objective Optimization Applied to Industrial Energy Problems, Swiss Federal Institute of Technology, 2002.

[51] M. Bürer, et al., Multi-criteria optimization of a district cogeneration plant integrating a solid oxide fuel cell - gas turbine combined cycle, heat pumps and chillers energy, Int. J., 28 (2003) 497-518.

[52] X. Pelet, et al., Multi-objective optimization of integrated energy systems for remote communities considering economic and $\mathrm{CO}_{2}$ emissions, Int. J. Thermal Sci., 44 (2005) 1180-1189. 